\title{
Stability of Three-Dimensional Slurry Trenches with Inclined Ground Surface: A Theoretical Study
}

\author{
Xiao-Fei Jin, ${ }^{1}$ Shu-Ting Liang, ${ }^{1}$ and Xiao-Jun $\mathrm{Zhu}^{2}$ \\ ${ }^{1}$ School of Civil Engineering, Southeast University, Nanjing 210096, China \\ ${ }^{2}$ Architectural Design and Research Institute, Southeast University, Nanjing 210096, China \\ Correspondence should be addressed to Shu-Ting Liang; stliang@seu.edu.cn
}

Received 29 April 2015; Accepted 24 May 2015

Academic Editor: João M. P. Q. Delgado

Copyright (C) 2015 Xiao-Fei Jin et al. This is an open access article distributed under the Creative Commons Attribution License, which permits unrestricted use, distribution, and reproduction in any medium, provided the original work is properly cited.

\begin{abstract}
Stability of slurry trenches is an important issue during the construction of the groundwater cutoff walls and diaphragm walls, and thus gradually draws attention. In this paper, a theoretical method for a three-dimensional trench model with an inclined ground was proposed. Based on the Coulomb-type force equilibrium, a safety factor assessing the stability was derived. The results showed that the existing two-dimensional model was conservative compared to the present three-dimensional model; concretely, a greater inclined angle of the inclined ground and trench length decreased the safety factor. This work could be used to assess the trench stability for both $2 \mathrm{D}$ and $3 \mathrm{D}$ cases with inclined ground surfaces.
\end{abstract}

\section{Introduction}

Slurry trenches are often used as a hydraulic barrier to prevent the groundwater from flowing into the trenches during the construction of groundwater cutoff walls and diaphragm walls, and the slurry in the excavated trenches plays an important role in providing a lateral supporting force to the trench walls before backfilling. Therefore, slurry trench stability is a major concern. However, most of the existing studies focused on the ground movements and stress relief induced by diaphragm wall construction: Poh and Wong concluded that evaluated aspects of performance include lateral and vertical soil movements during the construction of the test wall panel [1]; Ng and Yan confirmed the horizontal arching and downward load transfer mechanisms during diaphragm wall installation using the finite difference method [2]; Gourvenec and Powrie investigated the impact of three-dimensional effects and panel length on horizontal ground movements and changes in lateral stress during the sequential installation of a number of diaphragm wall panels [3]; Ng and Lei derived an analytical solution for calculating horizontal stress changes and displacements caused by the excavation for a diaphragm wall panel [4]; Schäfer and Triantafyllidis investigated the influence of a diaphragm wall construction on the stress field in a soft clayey soil [5]; Arai et al. conducted to examine ground movement and stress after the installation of circular diaphragm walls and soil excavation within the walls [6]; Conti et al. studied the mechanisms of load transfer and the deformations of the ground during slurry trenching and concreting in dry sand [7]; Comodromos et al. proposed a new approach for simulating the excavation and construction of subsequent panels to investigate the effects from the installation of diaphragm walls on the surrounding and adjacent buildings [8]; Lei et al. proposed an approximate analytical solution to predict ground surface settlements along the centre-line perpendicular to a slurry-supported diaphragm wall panel [9]. Until now, the problem of the slurry trench stability gradually receives much attention in underground engineering. In fact, in the early stage, a two-dimensional limit equilibrium method for trench stability based on a simple Coulomb wedge for dry soil conditions was developed [10]; later, the method was extended to account for influences of different levels of slurry in the trench and groundwater in the cohesionless soil [11]. Moreover, based on the Rankin theorem, the trench stability was assessed by considering the pressures from soils, hydrostatic slurry, and groundwater [12]. However, these mentioned methods treated the trench stability as 
a two-dimensional problem and neglected stabilizing forces or shear forces acting on both ends of the failure mass, which may produce conservative results. Indeed, considering the real case including contribution of the shear forces on the both ends of the failure wedge, three-dimensional method derived from the two-dimensional limit equilibrium theory was already used to analyze the trench stability; Prater [13] and Washbourne [14] proposed planar sides to enhanced existing two-dimensional models. Nonplanar sides also were proposed $[15,16]$ and may yield a closer approximation to the curved geometry observed for trench failure surfaces [14, 17]; Fox presented Coulomb-type force equilibrium analyses for general three-dimensional stability of a slurry-supported [18].

Stability analyses using the methods from the abovementioned works have already taken into account the influences of several primary design parameters, including trench length and depth, slurry depth and density, groundwater depth, and tension crack. However, if cutoff walls locate below an inclined ground, it is necessary to consider the effect of the inclined ground surface on the trench stability. In this regard, $\mathrm{Li}$ et al. investigated the influence of inclination angle on trench stability by a two-dimensional model, and they showed that it was unconservative to neglect ground surface inclination when analyzing trench stability [19].

Here, extending the two-dimensional model of Li et al. [19] to three-dimensional case, we presented an analytical solution of the safety factor and critical failure angle for a slurry-supported trench with an inclined ground, and an example was finally discussed to illustrate the variation of the safety factor and critical failure angle with different inclined angle, trench length, and groundwater depth.

\section{Theory}

A three-dimensional model of a failure wedge with length $l$ and force analysis of the model are shown in Figure 1. In this model, the top surface of slurry is assumed to be higher than that of the groundwater surface (i.e., $h_{s}>h_{w}$ ), and the trench walls were considered to be impermeable after the excavation, because there existed a layer of gradually thickened filter cake-like bentonite, which results in independency between the pore pressure in the soil and slurry pressure in the trench. It is worth mentioning that the shear strength due to soil suctions above the groundwater surface can be included by specifying an appropriate value for $c_{1}^{\prime}$, which is called effective stress cohesion intercept above groundwater surface, according to the total cohesion method $[18,20]$. Besides, the wedge was assumed to be rigid, and temporary loads were considered uniformly distributed, and the geometric parameters $l_{1}, l_{2}, a, b$, and $c$ in Figure 1 satisfy $l_{1}=(\cos \beta / \sin (\theta-\beta)) h, l_{2}=h_{w} \csc \theta, a=l_{1} \cos \theta-h \cot \theta$, $b=l_{1} \cos \theta$, and $c=h \cot \theta$, in which $\theta$ and $\beta$ are angles made by the failure plane and inclined ground with respect to the horizontal plane, respectively, and $h$ is the depth of the trench.

Considering the three-dimensional case different from the two-dimensional case by Li et al. [19], the shear resistance force $S$ acting on end planes of the wedge is treated to be parallel to the failure plane (see Figures $1(\mathrm{~b})$ and $1(\mathrm{c})$ ). The shear resistance force is assumed to be uniformly distributed along the failure plane, and its magnitude proportionally varies; thus, the progressive failure effect can be neglected and the safety factor with respect to shear failure of each end plane is equal to that of the failure plane [18]. The total shear force on each end plane of the wedge is calculated as

$$
S=S_{1}+S_{2},
$$

where $S_{1}$ and $S_{2}$ are shear resistant forces acting on two portions of each end plane of the wedge, respectively, that is, above (I) and below (II and III) the horizontal plane; see Figure 1(c).

For the portion (I) above the horizontal plane of the wedge, through the force analysis, $S_{1}$ can be expressed as

$$
\begin{aligned}
S_{1} & =\frac{1}{F}\left(\int_{0}^{b} \int_{-\tan \beta x}^{0}\left(c_{1}^{\prime}+\sigma_{h 1,1}^{\prime} \tan \phi^{\prime}\right) d z d x\right. \\
& \left.-\int_{c}^{b} \int_{(-b \tan \beta / a)(x-c)}^{0}\left(c_{1}^{\prime}+\sigma_{h 2,1}^{\prime} \tan \phi^{\prime}\right) d z d x\right) \\
& =\frac{h^{2}}{2 F}\left(c_{1}^{\prime} \tan \beta \frac{\cot \theta}{\tan \theta-\tan \beta}+\frac{1}{4} K \gamma_{1} \tan \phi^{\prime}(\tan \beta)^{2}\right. \\
& \cdot h \frac{\cot \theta}{(\tan \theta-\tan \beta)^{2}}+K q \tan \phi^{\prime}\left(\frac{1}{\tan \theta-\tan \beta}\right. \\
& -\cot \theta)),
\end{aligned}
$$

where $q$ is the uniformly distributed temporary load on the inclined ground surface, $F$ is the safety factor, $\gamma_{1}$ and $c_{1}^{\prime}$ are the unit weight and effective stress cohesion intercept of the soil above the groundwater surface, respectively, $\phi^{\prime}$ is the effective stress friction angle of the entire soil profile, $K$ taken as the at-rest lateral earth pressure coefficient $K_{0}=1-\sin \phi^{\prime}$ is the average lateral earth pressure coefficient for the end planes of the failure wedge, and the horizontal effective stresses are

$$
\begin{aligned}
& \sigma_{h 1,1}^{\prime}=K\left(q+\gamma_{1} \frac{x}{b}(z+x \tan \beta)\right), \\
& x \in[0, b], z \in[-\tan \beta x, 0], \\
& \sigma_{h 2,1}^{\prime}=K\left(q+\gamma_{1} \frac{x-c}{a}\left(z+\frac{b \tan \beta}{a}(x-c)\right)\right), \\
& x \in[c, b], z \in\left[-\frac{b \tan \beta}{a}(x-c), 0\right] .
\end{aligned}
$$

For the shear resistance force $S_{2}$ acting on the portion (II and III) below the horizontal plane, it can be calculated as

$$
\begin{aligned}
S_{2} & =\frac{1}{F}\left(\int_{0}^{z_{w}} \int_{0}^{-c z / h+c}\left(c_{1}^{\prime}+\sigma_{h 1,2}^{\prime} \tan \phi^{\prime}\right) d x d z\right. \\
& \left.+\int_{z_{w}}^{h} \int_{0}^{-c z / h+c}\left(c_{2}^{\prime}+\sigma_{h 2,2}^{\prime} \tan \phi^{\prime}\right) d x d z\right) \\
& =\frac{\cot \theta}{2 F}\left\{\frac { K \operatorname { t a n } \phi ^ { \prime } } { 3 } \left[3 q h^{2}+\gamma_{2} h^{3}\right.\right.
\end{aligned}
$$




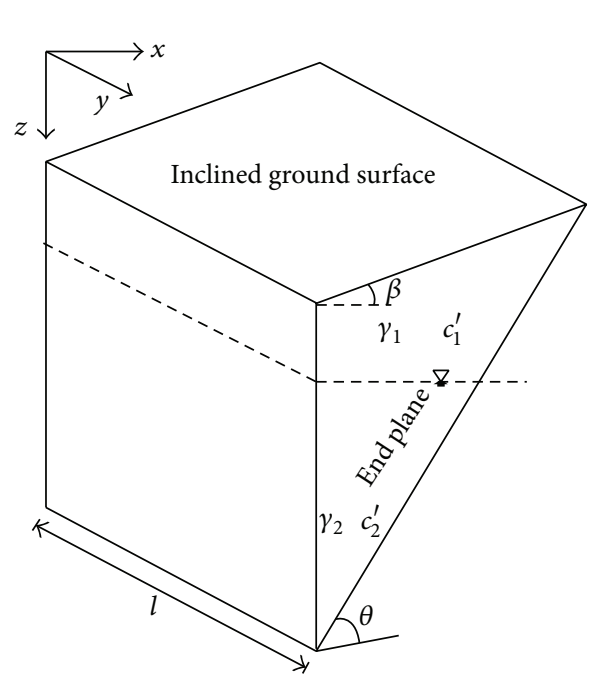

(a)

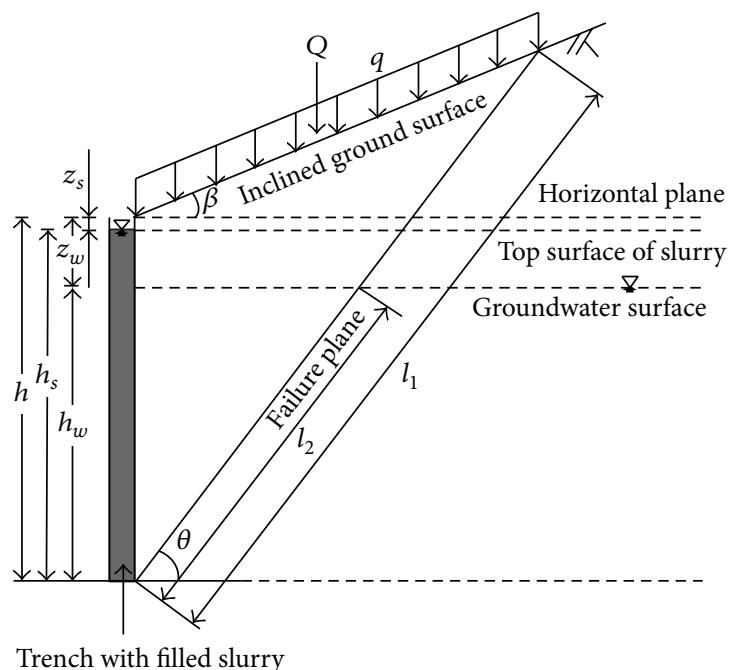

(b)

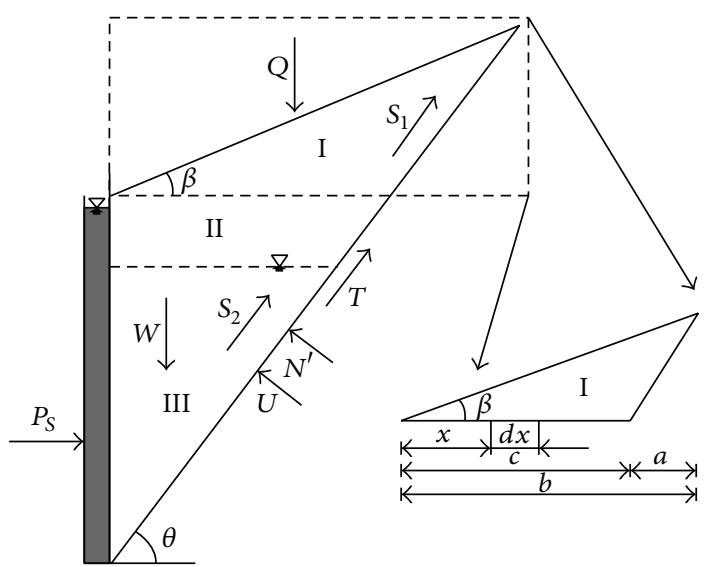

(c)

FIgURE 1: Three-dimensional failure wedge. (a) Schematic model of failure wedge, (b) definitions of geometric parameters, and (c) force analysis.

$$
\begin{aligned}
& \left.+z_{w}\left(\gamma_{1}-\gamma_{2}\right)\left(z_{w}^{2}-3 h z_{w}+3 h^{2}\right)\right]+z_{w}\left(c_{1}^{\prime}-c_{2}^{\prime}\right) \\
& \left.\cdot\left(2 h-z_{w}\right)+c_{2}^{\prime} h^{2}\right\},
\end{aligned}
$$

where $\gamma_{2}$ and $c_{2}^{\prime}$ are the unit weight and effective stress cohesion intercept of the soil below the groundwater surface, respectively, $z_{w}$ is the distance between the horizontal plane and groundwater surface, and the horizontal effective stresses are

$$
\begin{array}{r}
\sigma_{h 1,2}^{\prime}=K\left(q+\gamma_{1} \frac{x^{2} \tan \beta}{b}+\gamma_{1} z\right), \quad z \in\left[0, z_{w}\right], \\
\sigma_{h 2,2}^{\prime}=K\left(q+\gamma_{1} \frac{x^{2} \tan \beta}{b}+\gamma_{1} z_{w}+\gamma_{2}\left(z-z_{w}\right)\right), \\
z \in\left[z_{w}, h\right] .
\end{array}
$$

Substituting (2) and (4) into (1), the total shear resistance force applied on each end plane is

$$
S=\frac{\Phi}{F},
$$

where

$$
\begin{aligned}
\Phi & =\frac{1}{2} \tan \beta h^{2} \frac{\cot \theta}{(\tan \theta-\tan \beta)^{2}}\left[c_{1}^{\prime}(\tan \theta-\tan \beta)\right. \\
& \left.+\frac{1}{4} K \gamma_{1} \tan \phi^{\prime} \tan \beta h\right]+\frac{K \tan \phi^{\prime}}{6}\left[\frac{3 q h^{2}}{\tan \theta-\tan \beta}\right. \\
& +\gamma_{2} h^{3} \cot \theta \\
& \left.+z_{w}\left(\gamma_{1}-\gamma_{2}\right)\left(z_{w}^{2}-3 h z_{w}+3 h^{2}\right) \cot \theta\right] \\
& +\frac{\cot \theta}{2}\left[z_{w}\left(c_{1}^{\prime}-c_{2}^{\prime}\right)\left(2 h-z_{w}\right)+c_{2}^{\prime} h^{2}\right] .
\end{aligned}
$$


For the entire wedge, the force equilibrium in the directions normal and tangential to the failure plane yields

$$
\begin{aligned}
& \sum F_{N}=N^{\prime}+U-(W+Q) \cos \theta-P_{S} \sin \theta=0, \\
& \sum F_{T}=2 S+T-(W+Q) \sin \theta+P_{S} \cos \theta=0,
\end{aligned}
$$

where $W$ is the soil weight, $Q$ is the equivalent concentrated force by $q, P_{S}$ is the lateral force by filled slurry, $U$ is the hydrostatic groundwater force, $N^{\prime}$ is the effective normal force, and $T$ is the shear force on the failure plane. Through the calculations of the forces in (8), they are expressed

$$
\begin{aligned}
& \frac{W+Q}{l}=\Gamma=\frac{h}{\tan \theta-\tan \beta}\left(q+\frac{h \gamma_{1}}{2}\right) \\
& +\frac{\left(\gamma_{2}-\gamma_{1}\right) h_{w}^{2}}{2 \tan \theta}, \\
& \frac{T}{l}=\frac{1}{F}\left(\Psi+\frac{N^{\prime} \tan \phi^{\prime}}{l}\right)=\frac{1}{F}\left(c_{1}^{\prime} h \frac{\cos \beta}{\sin (\theta-\beta)}\right. \\
& \left.+\left(c_{2}^{\prime}-c_{1}^{\prime}\right) h_{w} \csc \theta+\frac{N^{\prime} \tan \phi^{\prime}}{l}\right), \\
& \frac{U}{l}=\Lambda=\frac{\gamma_{w} \csc \theta h_{w}^{2}}{2}, \\
& \frac{P_{S}}{l}=\Omega=\frac{\gamma_{s} h_{s}^{2}}{2}
\end{aligned}
$$

in the expression of $P_{S} / l$, and $\gamma_{s}$ and $h_{s}$ are unit weight and the height of the filled slurry, respectively.

Solving (8) for the safety factor of the wedge, the following is obtained:

$$
\begin{aligned}
F & =\frac{2 \Phi}{(\Gamma \sin \theta-\Omega \cos \theta) l}+\frac{\Psi}{\Gamma \sin \theta-\Omega \cos \theta} \\
& +\left(\frac{\Gamma}{\Gamma \tan \theta-\Omega}+\frac{\Omega}{\Gamma-\Omega \cot \theta}\right. \\
& \left.-\frac{\Lambda}{\Gamma \sin \theta-\Omega \cos \theta}\right) \tan \phi^{\prime} .
\end{aligned}
$$

The critical angle $\theta_{\mathrm{cr}}$ of the failure plane that corresponds to the minimum safety factor $F_{S}$ for the failure wedge is found by taking $d F / d \theta=0$, and the equation can be solved by an iterative method. It is noted that the solution of $\theta_{\mathrm{cr}}$ should locate in the range $45^{\circ} \leq \theta_{\mathrm{cr}} \leq 90^{\circ}$; otherwise $F_{S}$ will be less than zero if $\theta_{\mathrm{cr}}<45^{\circ}$ [18].

Considering a peculiar case of cohesionless soils (i.e., $c_{1}^{\prime}=$ $\left.c_{2}^{\prime}=0\right)$, the expression of $F$ reduces to

$$
F=f(\theta) \tan \phi^{\prime}
$$

where

$$
\begin{aligned}
f(\theta) & =\frac{2 \Pi}{(\Gamma \sin \theta-\Omega \cos \theta) l}+\frac{\Gamma}{\Gamma \tan \theta-\Omega} \\
& +\frac{\Omega}{\Gamma-\Omega \cot \theta}-\frac{\Lambda}{\Gamma \sin \theta-\Omega \cos \theta}, \\
\Pi & =\Phi \cot \phi^{\prime}, \\
\Pi & =\frac{1}{8} K \gamma_{1}(\tan \beta)^{2} h^{3} \frac{\cot \theta}{(\tan \theta-\tan \beta)^{2}}+\frac{1}{6} \\
& \cdot K\left[\frac{3 q h^{2}}{\tan \theta-\tan \beta}\right. \\
& +\gamma_{2} h^{3} \cot \theta \\
& \left.+z_{w}\left(\gamma_{1}-\gamma_{2}\right)\left(z_{w}^{2}-3 h z_{w}+3 h^{2}\right) \cot \theta\right] .
\end{aligned}
$$

Equation (11) indicates that $\theta_{\mathrm{cr}}$ is independent of $\phi^{\prime}$, which is consistent with the analytical result for the horizontal ground by Fox [18]. The proposed analytical method is also applicable when the ground is sloping away from the trench (i.e., $\beta<0$ ). Under this condition, the intersection point of the inclined ground surface and the failure plane should be above the groundwater surface (i.e., $l_{1}>l_{2}$ ).

\section{Example}

Here, we investigate the influences of different ground inclinations and trench lengths on the trench stability. The geometric and physical parameters of the trench, soil, and slurry are from Fox [21], namely, $h=20 \mathrm{~m}, h_{s}=20 \mathrm{~m}$, $z_{w}=3 \mathrm{~m}, \gamma_{s}=11.8 \mathrm{kN} / \mathrm{m}^{3}, \gamma_{1}=19.0 \mathrm{kN} / \mathrm{m}^{3}, c_{2}^{\prime}=0 \mathrm{kPa}$, $\gamma_{2}=20.0 \mathrm{kN} / \mathrm{m}^{3}, \phi^{\prime}=37^{\circ}$, and $q=0 \mathrm{kN} / \mathrm{m}^{2}$. Moreover, $c_{1}^{\prime}=10 \mathrm{kPa}$ is used for the soil above the groundwater surface to consider the soil suction effect.

Figure 2 shows the relationships of the minimum safety factor $F_{S}$ or critical angle $\theta_{\text {cr }}$ versus inclined angle $\beta$ for the two-dimensional case. In Figure 2(a), we can see that $F_{S}$ is negatively relevant with $\beta$, and $F_{S}$ decreases from 1.48 to 1.19 as $\beta$ varies from $0^{\circ}$ to $15^{\circ}$. This indicates that the assumption of a horizontal ground (i.e., $0^{\circ}$ ) for the inclined ground results in an overestimation of the trench stability, which may result in sliding failure of the excavated panel. When the inclined angle $\beta$ comes down into negative value for a specific case $\beta=-10^{\circ}, F_{S}$ equals 1.74 , which is greater than 1.48 for $\beta=0^{\circ}$. And more, the present prediction is comparable to that based on Rankin's earth pressure theory (the dashed line in Figure 2(a), Morgenstern and Amir-Tahmasseb, 1965 [11]), which validates our derived theory, and is also equal to the calculated values with the method proposed by Li et al. [19]. With the given $\theta_{c r}$, engineers can calculate the size of the potential failure mass, and reinforcement design can be made if the trench stability is not satisfactory; for example, when $\beta=0^{\circ}$ and $\theta_{\mathrm{cr}}=58.56^{\circ}$, the area of the end crosssection is $22.6 \%$ greater than that for $\theta_{\mathrm{cr}}=45^{\circ}+\phi^{\prime}\left(=63.5^{\circ}\right)$. In Figure $2(\mathrm{~b})$, it is readily seen that $\theta_{\mathrm{cr}}$ decreases and then 


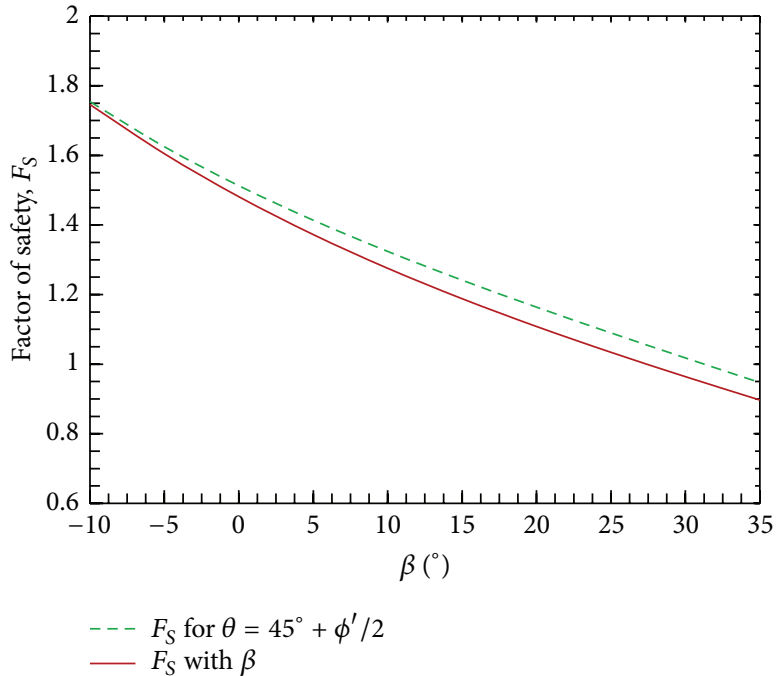

(a)

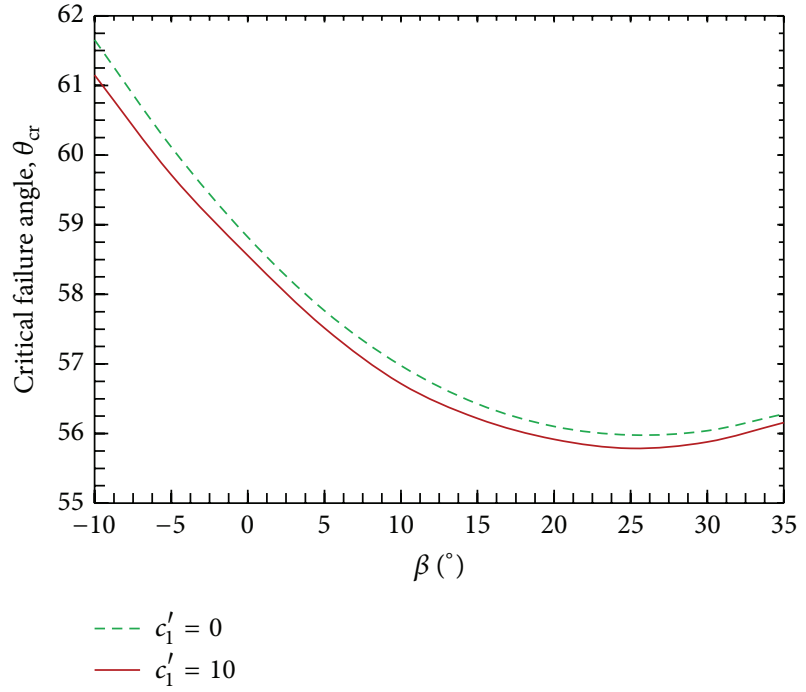

(b)

Figure 2: Influences of the inclined angle $\beta$ on (a) $F_{S}$ and (b) $\theta_{\text {cr }}$.

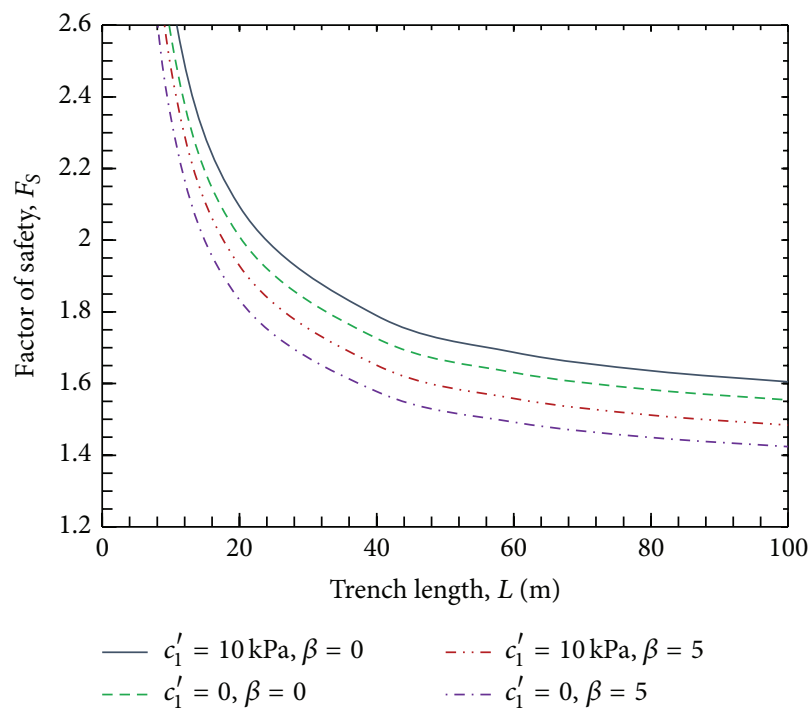

(a)

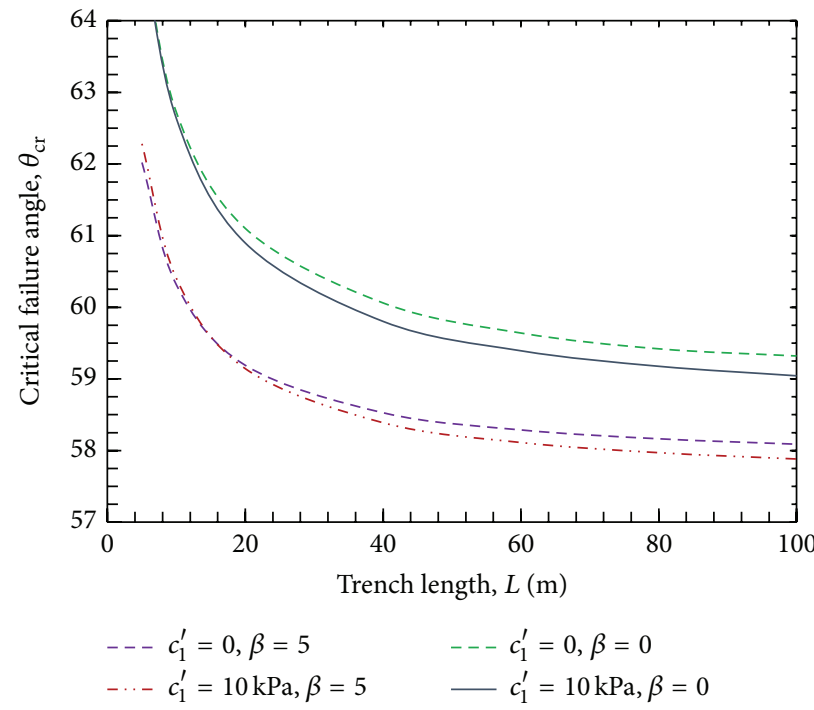

(b)

FIgURE 3: Influences of the trench length $L$ on (a) $F_{S}$ and (b) $\theta_{\text {cr. }}$.

increases as $\beta$ changes from $-10^{\circ}$ to $35^{\circ}$, and the minimum value $\theta_{\text {cr }}=56^{\circ}$ is obtained when $\beta=25^{\circ}$. This again shows that it is necessary to determine $\theta_{\text {cr }}$ instead of using $\theta_{\text {cr }}=$ $45^{\circ}+\phi^{\prime}$. Plus, Figure 2(b) also shows that increasing $c_{1}^{\prime}$ tends to a reduced value of $\theta_{\text {cr. }}$.

The influences of the trench length $L$ on $F_{S}$ and $\theta_{\text {cr }}$ are plotted in Figure 3. It shows that $F_{S}$ is obviously affected by the trench length $L$, and the results of the present threedimensional case move toward the two-dimensional case as $L$ tends to infinity. Figure 3(a) shows that increasing $c_{1}^{\prime}$ and $\beta$ results in increasing and decreasing $F_{S}$, respectively. For this example, values of the trench length $L$ which correspond to $F_{S}$ equalling 1.8 are $39.3 \mathrm{~m}, 34.8 \mathrm{~m}, 29.3 \mathrm{~m}$, and $22.6 \mathrm{~m}$ for $c_{1}^{\prime}=10 \mathrm{kPa}(\beta=0), c_{1}^{\prime}=0 \mathrm{kPa}(\beta=0), c_{1}^{\prime}=10 \mathrm{kPa}(\beta=5)$, and $c_{1}^{\prime}=0 \mathrm{kPa}(\beta=5)$, respectively, whereas, corresponding to $c_{1}^{\prime}$ and $\beta, F_{S}$ is calculated as $1.48,1.44,1.37$, and 1.32 for the two-dimensional case, respectively. Figure 3(b) shows that $\theta_{\mathrm{cr}}$ decreases with increasing trench length $L$, and increasing both $c_{1}^{\prime}$ and $\beta$ results in decreasing $\theta_{\mathrm{cr}}$, and $\theta_{\mathrm{cr}}$ is apparently affected by $\beta$. For this example, values of $\theta_{\text {cr }}$ that correspond to $L=40$ are $59.8 \mathrm{~m}, 58.4 \mathrm{~m}, 60.1 \mathrm{~m}$, and $58.5 \mathrm{~m}$ for $c_{1}^{\prime}=$ $10 \mathrm{kPa}(\beta=0), c_{1}^{\prime}=10 \mathrm{kPa}(\beta=5), c_{1}^{\prime}=0 \mathrm{kPa}(\beta=0)$, and $c_{1}^{\prime}=0 \mathrm{kPa}(\beta=5)$, respectively.

Finally, based on the parameters $L=40 \mathrm{~m}$ and $\beta=5^{\circ}$, the influence of the rising groundwater on the safety factor is shown in Figure 4. It is noticed that larger $z_{w}$ represents lower 


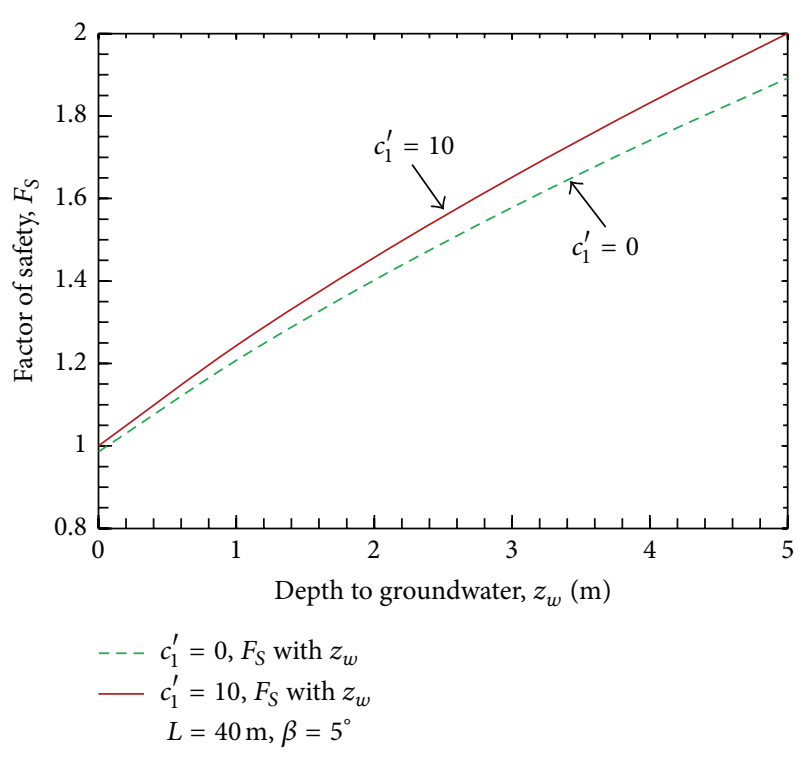

Figure 4: Influence of the depth of groundwater $z_{w}$ on $F_{S}$.

groundwater surface. Then, Figure 4 shows that increasing both $z_{w}$ and $c_{1}^{\prime}$ produces an increasing safety, and this can be easily understood.

\section{Conclusions}

In this paper, we have presented an analytical solution of the safety factor for the three-dimensional model of a slurry trench with an inclined ground surface. The solution includes several parameters, such as the inclined angle of the inclined ground surface, trench length and depth, slurry depth, temporary load, and groundwater surface elevation. The results showed that increasing inclined angle $\beta$ and trench length $L$ results in decreasing the safety factor, but increasing the depth to groundwater $z_{w}$ and suction effect $c_{1}^{\prime}$ produces an increase in the safety factor; meanwhile, the existing two-dimensional model was conservative compared to the present three-dimensional model. The study could be useful to assess the trench stability for both $2 \mathrm{D}$ and $3 \mathrm{D}$ cases with inclined ground surface.

\section{Conflict of Interests}

The authors declare that there is no conflict of interests regarding the publication of this paper.

\section{Acknowledgments}

The financial support received from National Natural Science Foundation of China (NSFC), Grant no. 51208181, and Key Projects in the National Science \& Technology Pillar Program during the Twelfth Five-Year Plan Period, Grant no. 2011BAJ10B08, is gratefully acknowledged. The authors also thank Professor Dr. Qiang Chen, Southeast University, for the English correction.

\section{References}

[1] T. Y. Poh and I. H. Wong, "Effects of construction of diaphragm wall panels on adjacent ground: field trial," Journal of Geotechnical and Geoenvironmental Engineering, vol. 124, no. 8, pp. 749756, 1998.

[2] C. W. W. Ng and R. W. M. Yan, "Three-dimensional modelling of a diaphragm wall construction sequence," Geotechnique, vol. 49 , no. 6 , pp. 825-834, 1999.

[3] S. M. Gourvenec and W. Powrie, "Three-dimensional finiteelement analysis of diaphragm wall installation," Geotechnique, vol. 49, no. 6, pp. 801-823, 1999.

[4] C. W. W. Ng and G. H. Lei, "An explicit analytical solution for calculating horizontal stress changes and displacements around an excavated diaphragm wall panel," Canadian Geotechnical Journal, vol. 40, no. 4, pp. 780-792, 2003.

[5] R. Schäfer and T. Triantafyllidis, "Modelling of earth and water pressure development during diaphragm wall construction in soft clay," International Journal for Numerical and Analytical Methods in Geomechanics, vol. 28, no. 13, pp. 1305-1326, 2004.

[6] Y. Arai, O. Kusakabe, O. Murata, and S. Konishi, "A numerical study on ground displacement and stress during and after the installation of deep circular diaphragm walls and soil excavation," Computers and Geotechnics, vol. 35, no. 5, pp. 791$807,2008$.

[7] R. Conti, L. de Sanctis, and G. M. B. Viggiani, "Numerical modelling of installation effects for diaphragm walls in sand," Acta Geotechnica, vol. 7, no. 3, pp. 219-237, 2012.

[8] E. M. Comodromos, M. C. Papadopoulou, and G. K. Konstantinidis, "Effects from diaphragm wall installation to surrounding soil and adjacent buildings," Computers and Geotechnics, vol. 53, pp. 106-121, 2013.

[9] G. H. Lei, H. S. Sun, and C. W. W. Ng, "An approximate analytical solution for calculating ground surface settlements due to diaphragm walling," Computers and Geotechnics, vol. 61, pp. 108-115, 2014.

[10] J. K. T. L. Nash and G. K. Jones, "The support of trenches using fluid mud," in Proceedings of the Symposium on Grouts and Drilling Muds in Engineering Practice, pp. 177-180, Butterworths, London, UK, 1963.

[11] N. Morgenstern and I. Amir-Tahmasseb, "The stability of a slurry trench in cohesionless soils," Géotechnique, vol. 15, no. 4, pp. 387-395, 1965.

[12] P. P. Xanthakos, Slurry Walls as Structural Systems, McGrawHill, New York, NY, USA, 1994.

[13] E. G. Prater, “Die Gewölbewirkung der Schlitzwände," Der Bauingenieur, vol. 48, no. 4, pp. 125-131, 1973.

[14] J. Washbourne, "The three-dimensional stability analysis of diaphragm wall excavations," Ground Engineering, vol. 17, no. 4, pp. 24-29, 1984.

[15] A. Piaskowski and Z. Kowalewski, "Applications of thixotropic clay suspensions for stability of vertical sides of deep trenches without strutting," in Proceedings of the 6th International Conference on Soil Mechanics and Foundation Engineering, vol. 2, pp. 526-529, 1965.

[16] J.-S. Tsai and J.-C. Chang, "Three-dimensional stability analysis for slurry-filled trench wall in cohesionless soil," Canadian Geotechnical Journal, vol. 33, no. 5, pp. 798-808, 1996.

[17] J.-S. Tsai, L.-D. Jou, and H.-S. Hsieh, "A full-scale stability experiment on a diaphragm wall trench," Canadian Geotechnical Journal, vol. 37, no. 2, pp. 379-392, 2000. 
[18] P. J. Fox, "Analytical solutions for stability of slurry trench," Journal of Geotechnical and Geoenvironmental Engineering, vol. 130, no. 7, pp. 749-758, 2004.

[19] Y.-C. Li, Q. Pan, and Y.-M. Chen, "Stability of slurry trenches with inclined ground surface," Journal of Geotechnical and Geoenvironmental Engineering, vol. 139, no. 9, pp. 1617-1619, 2013.

[20] D. G. Fredlund and H. Rahardjo, Soil Mechanics for Unsaturated Soils, Wiley, New York, NY, USA, 1993.

[21] P. J. Fox, "Discussion of 'stability of long trenches in sand supported by bentonite-water slurry' by George M. Filz, Tiffany Adams, and Richard R. Davidson," Journal of Geotechnical and Geoenvironmental Engineering, vol. 132, no. 5, p. 666, 2006. 

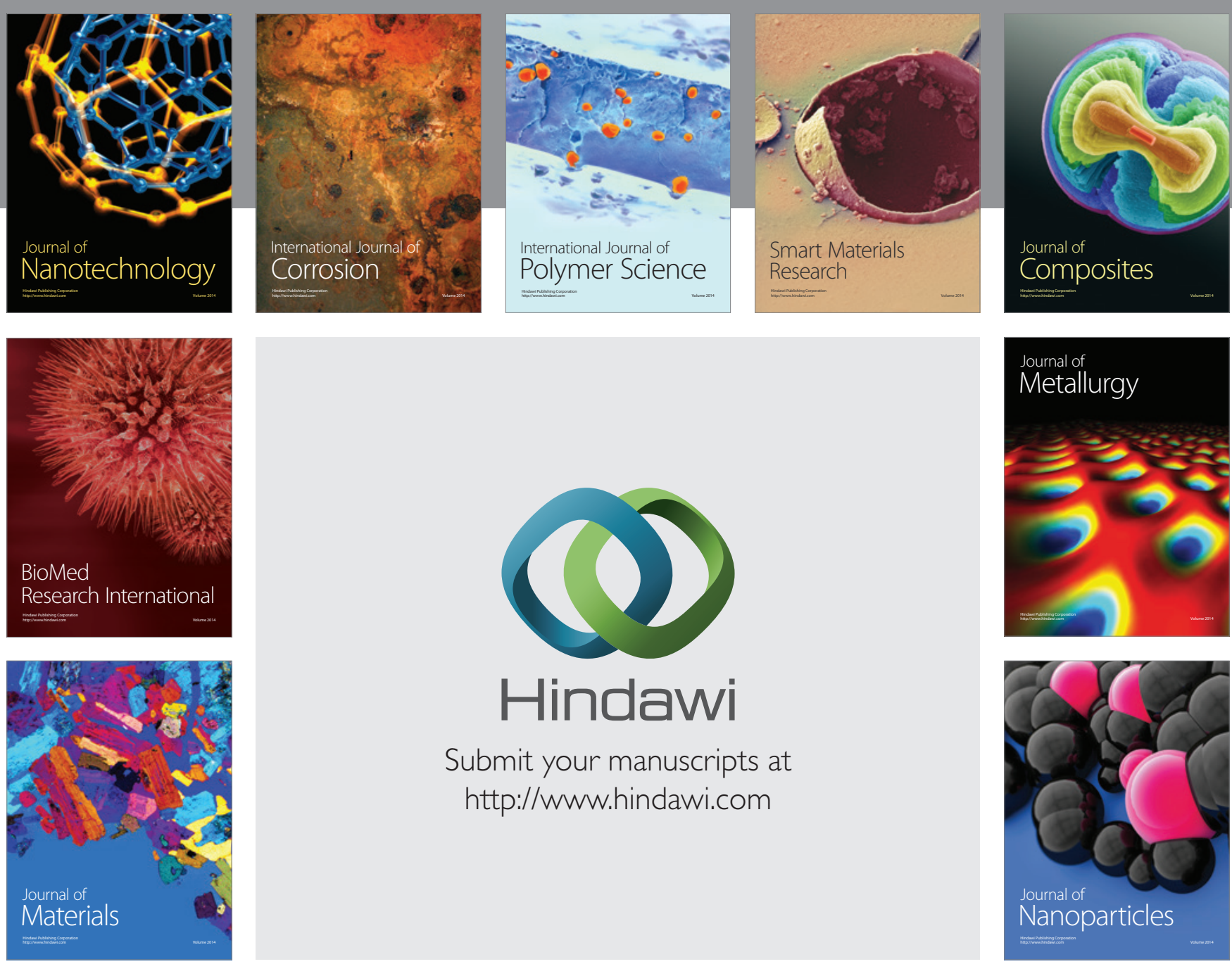

Submit your manuscripts at http://www.hindawi.com
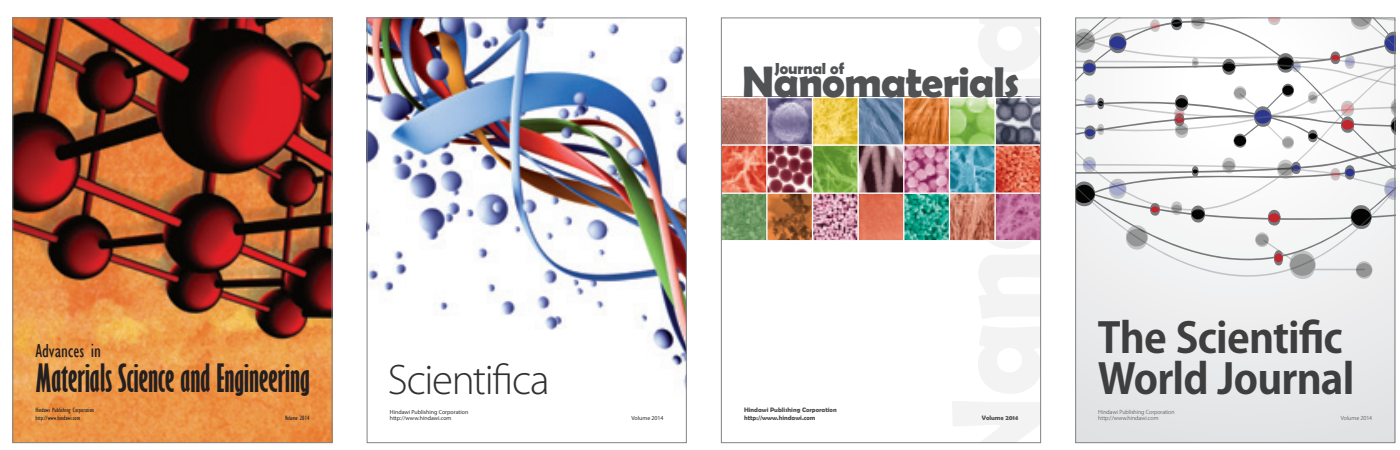

\section{The Scientific World Journal}
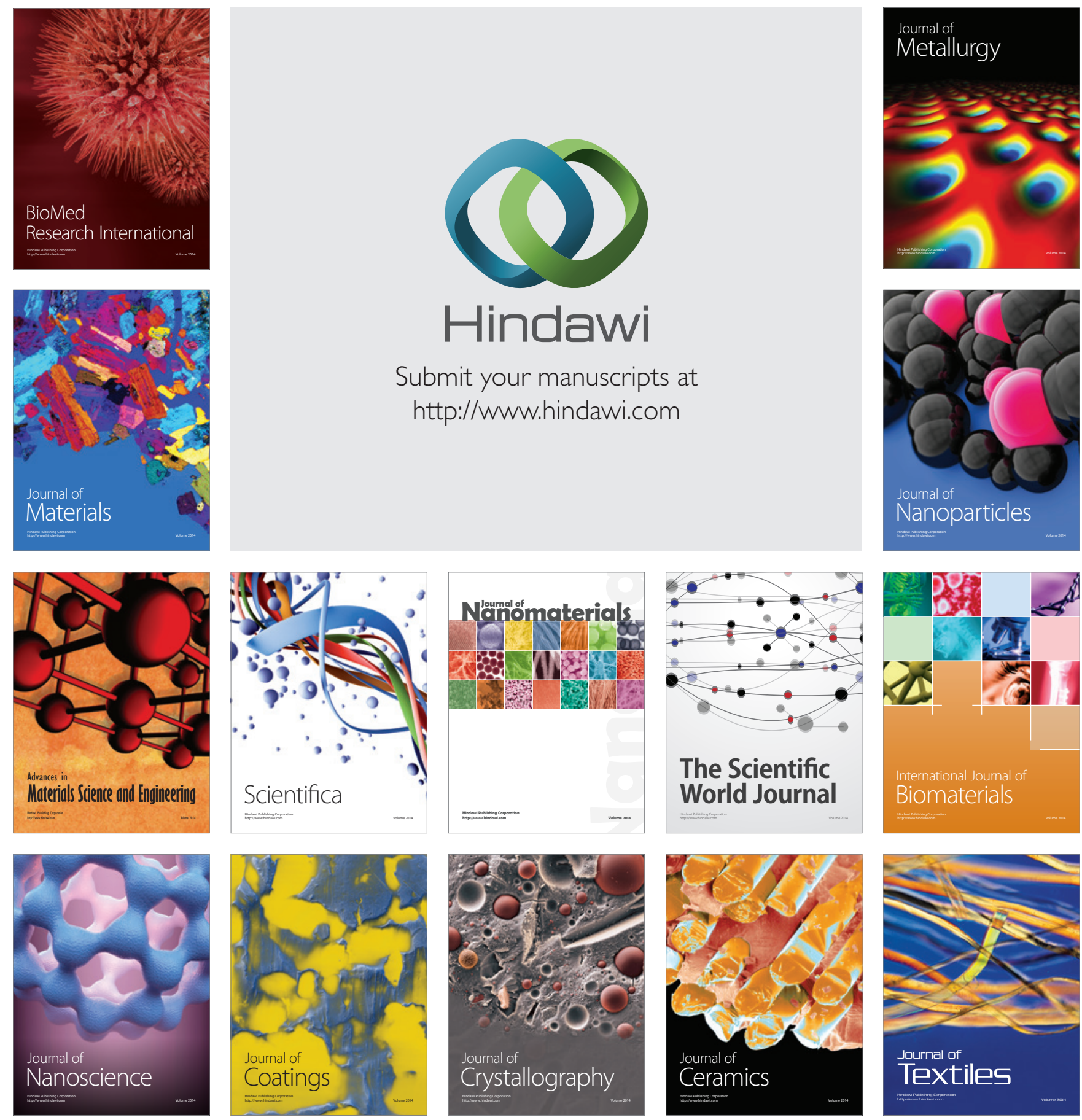